\title{
A PNEUMATICALLY-ACTUATED MICROVALVE FOR SPATIALLY-SELECTIVE CHEMICAL DELIVERY
}

\author{
Kyusuk Baek, Yang Li, Mayurachat Gulari, and Kensall D. Wise \\ Engineering Research Center for Wireless Integrated MicroSystems \\ The University of Michigan, Ann Arbor, MI 48109-2122
}

\begin{abstract}
This paper reports a drug-delivery probe (Figure 1) with onchip normally-open microvalves that are used in blocking mode, preventing flow to non-selected orifices and allowing drugs to be injected into spatially-localized areas of the brain to modify cellular activity. The present valves are driven pneumatically to allow detailed studies of valve operation, but will be used with onchip thermo-pneumatic actuators that operate from low voltage, produce negligible tissue heating, and have several microns of throw while holding off drive pressures as high as $50 \mathrm{kPa}$. For a valve having a diaphragm radius of $200 \mu \mathrm{m}$, the fully-open pressure drop at a flow rate of $513 \mathrm{pL} / \mathrm{sec}$ is only $7.4 \mathrm{kPa}$. For diaphragm radii of 180,200 , and $220 \mu \mathrm{m}$, leak rates of 32,21 , and $15 \mathrm{pL} / \mathrm{sec}$, respectively, are measured at an actuation pressure of $35 \mathrm{kPa}$.
\end{abstract}

\section{INTRODUCTION}

Silicon microelectrode arrays have become widely used in neurophysiological research over the past decade. Micro-electrode arrays capable of stimulating or recording from the nervous system are one of the principal tools used today for studying the central nervous system at the cellular level. They are also the basis for a number of neuroprosthetic devices being developed to address neurological disorders such deafness, blindness, epilepsy, paralysis and Parkinson's disease. To understand the cell function in an electrochemical system, there is growing interest in combining multi-site stimulating/ recording probes with the ability to deliver drugs to the nervous system with high spatial specificity, both for basic research in neuropharmacology and for possible use in neuro-prosthetics [1, 2]. For such probes, used for multi-site, multi-chemical injection, there must be a way to select the desired chemical and route it to the proper site in order to minimize the fluidic lead count. In this way, if two chemicals are to be used, there only three lines are needed for the implant: the first chemical, the second chemical, and perhaps a saline flushing solution. By being able to direct the fluid flow, any of the chemicals can be routed down any number of channels to the respective site. Without these capabilities, only the chemical in a particular line can be injected down that line to a single associated site. A separate line would be needed for each individual site, making multi-delivery site devices excessively tethered by external tubing coming off the back end. The solution to this situation requires onchip multiplexers (Figure 2), which are an integral part of every chemical delivery system in the macro world.

\section{REQUIREMENTS FOR MICROVALVES}

The integrated microvalves on a neural probe must be compatible with probe fabrication technology [1] without adding excessive complexity. They should also be robust and compatible

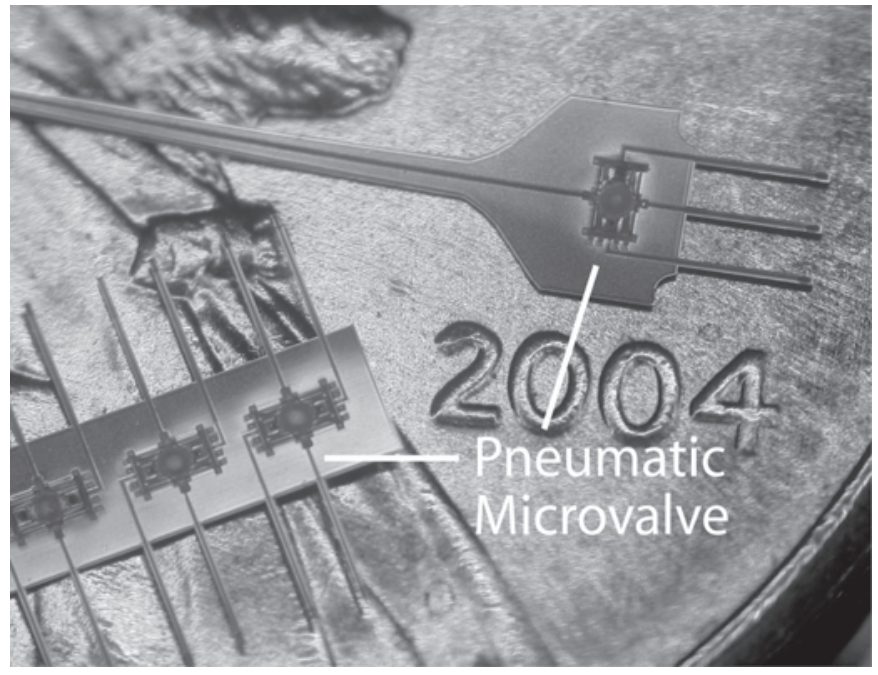

Figure 1. A drug delivery probe with integrated microvalves

with chronic use in-vivo. Due to the difficulty of replacing a chronic device, any such device needs long-term reliability ( $>5$ years) and packaging that is able to withstand the extracellular environment. The valves reported here will be used with the onchip thermo-pneumatic actuators in Figure 3. For thermopneumatic actuation, the use of high voltages within any living organism difficult due to the risk of electrical leakage and shock. In order to avoid damaging the neural system, a low actuation voltage $(<10 \mathrm{~V})$ is required. Any temperature rise in the tissue must be no more than $2{ }^{\circ} \mathrm{C}$ to avoid neural damage. Moreover, the entire delivery system must be kept small enough to avoid excessive tissue displacement and disruption of the cellular system.

Pressure ejection is the method used on the Michigan drug delivery probe. In operation, nitrogen pressure is applied at the back end of polyimide tubing, and the fluid in the channel moves in the direction of the pressure gradient. The flow rate is determined by the liquid properties, the applied pressure, and the channel cross-sectional area. A typical cortical neuron can be recorded electrically over a distance of roughly $50-100 \mu \mathrm{m}$. In order to effectively alter the neuronal environment, the minimum amount of injected chemical can arbitrarily be taken at about $10 \%$ of a $100 \mu \mathrm{m}$-diameter sphere, which is equivalent to about $50 \mathrm{pL}$. This amount of chemical is generally injected into the tissue in $100 \mathrm{mSec}$, resulting in a typical flow rate of $500 \mathrm{pL} / \mathrm{Sec}$, or $30 \mathrm{~nL} / \mathrm{min}$. Drugs have previously been delivered to tissue using a 1-2Psi pressure pulse having a duration of $100 \mathrm{msec}$ [2]. Recently, it has been observed that fast chemical injection can mechanically damage or even kill cells, so the trend is to deliver drugs over longer pulse-durations ( $5 \mathrm{nl}$ for $10 \mathrm{Sec})$ or to deliver smaller volumes of liquid with higher drug concentrations [3]. The minimum acceptable leak rate varies greatly among target 
and into the lightly-doped silicon beneath. Once formed, the trenches are connected by undercutting the undoped silicon between the trenches to form channels using 50 minutes in ethylenediamene pyrocatchol (EDP) at $110{ }^{\circ} \mathrm{C}$ (Figure $\left.4 \mathrm{a}, \mathrm{b}\right)$. An unsealed $20 \sim 25 \mu \mathrm{m}$-deep channel is formed with shallow boron ribs on the ceiling spaced by the trench areas. Then, low-pressure chemical vapor deposited (LPCVD) $1.2 \mu \mathrm{m}$ thick- $\mathrm{SiO}_{2} / \mathrm{Si}_{3} \mathrm{~N}_{4} / \mathrm{SiO}_{2}$, which normally isolates the electrodes from the substrate, also seals the channel by filling in the trench gaps (Figure 4c). Wider openings not fully sealed by stacked dielectrics still have enough space to deliver actuation pressure. Following the formation of the microchannels in the probe substrate, the space between the substrate and the valve diaphragm is formed using a $3 \mu \mathrm{m}$-thick CVD sacrificial polysilicon layer. Stress-compensated $1 \mu \mathrm{m}$-thick silicon oxide/silicon nitride/silicon oxide dielectrics are then deposited to form the corrugated diaphragm itself (Figure 4d). Etch access holes are formed around the perimeter of the diaphragm to allow removal of this first sacrificial polysilicon layer. The sacrificial layer is removed using a 3-hour tetramethyl ammonium hydroxide (TMAH) etch (Figure 5). After diaphragm release, the etch holes are filled by depositing additional silicon nitride/silicon dioxide dielectric. A $3 \mu \mathrm{m}$-thick sacrificial

Figure 2. The probe with multi-shanks and microvalves

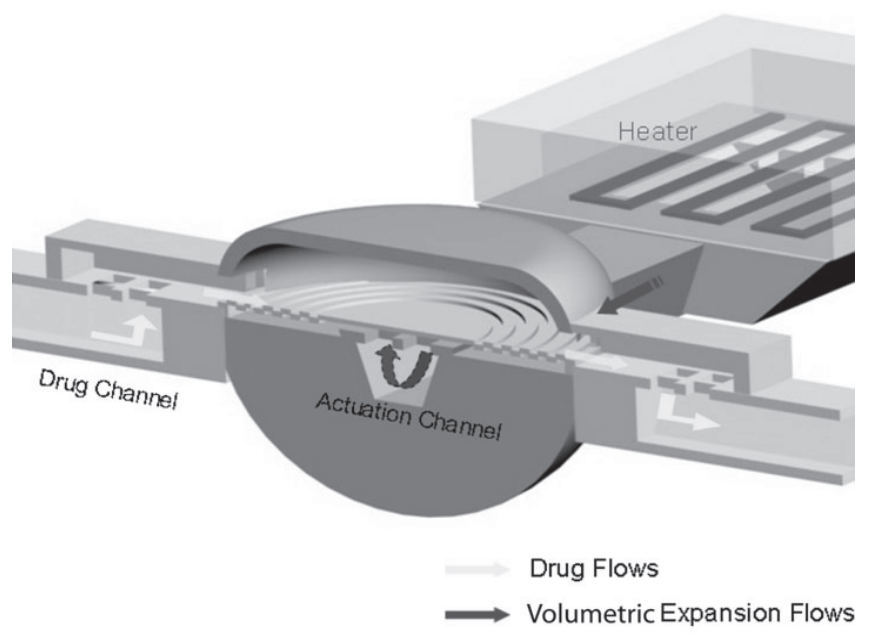

Figure 3. A diagram of the thermopneumatic microvalve

be taken at about $0.5 \%$ of a $100 \mu \mathrm{m}$-diameter sphere, which is equivalent to about $2.5 \mathrm{pL}$. For example, for a $100 \mathrm{mSec}$ pulse duration, the leak rate should be less than $25 \mathrm{pL} / \mathrm{Sec}$.

\section{FABRICATION}

Fabrication should be compatible with a standard buriedchannel probe process that allows electrical recording and stimulation as well as integrated flowmeters [4] on the same structure. The basic microvalve structure used is shown in Figure 3 and is realized using a 13-mask process. Fabrication of the microvalve takes only two masks in addition to the normal probe with microchannels [5]. The process begins with blank (100) silicon wafers. The first step is to define the probe shape using a patterned a $1.2 \mu \mathrm{m}$-thick silicon dioxide layer grown over the entire wafer in about 3 hours at a temperature of $1100^{\circ} \mathrm{C}$. The second step forms the buried channels. Screen masking structures with $2 \mu \mathrm{m}$ openings are patterned along the $\langle 110\rangle$ direction in the silicon. $4 \mu \mathrm{m}$ openings are used for the output port of the actuation channel, which delivers driving pressure to the corrugated diaphragm. $4 \mu \mathrm{m}$-deep trenches for the channels and corrugations of the valve diaphragm are etched with a deep reactive ion etcher (DRIE), which selectively etches silicon anisotropically by creating a chemically-reactive RF plasma and a DC bias. This etching process needs to penetrate through the shallow boron layer

Figure 4. (a) Drug-delivery microchannel after EDP etching, (b) Actuation channels after EDP (c) Top view of actuation channel after filling in trench gaps through stacked dielectrics (d) Cross-section view of corrugation diaphragm after covering CVD polysilicon by stacked dielectrics

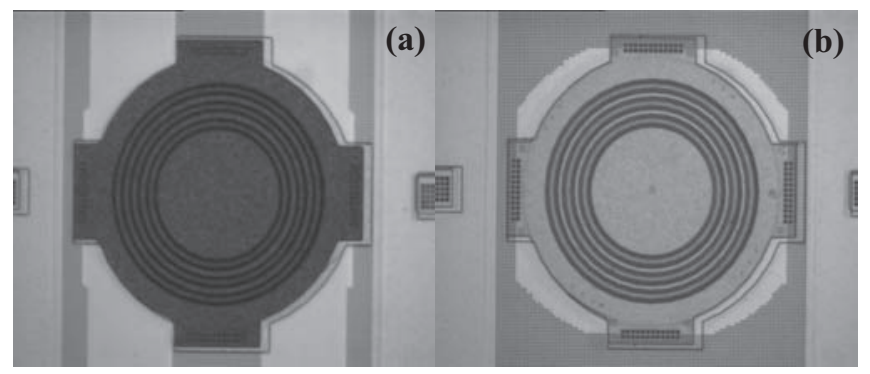

Figure 5. (a) Dark circular shape in diaphragm area is the CVD sacrificial polysilicon. (b) After diaphragm release, fully etched out cavity is shown through the transparent diaphragm made of silicon dioxide/ silicon nitride/ silicon dioxide. The cavity is connected to actuation channel through wider openings 


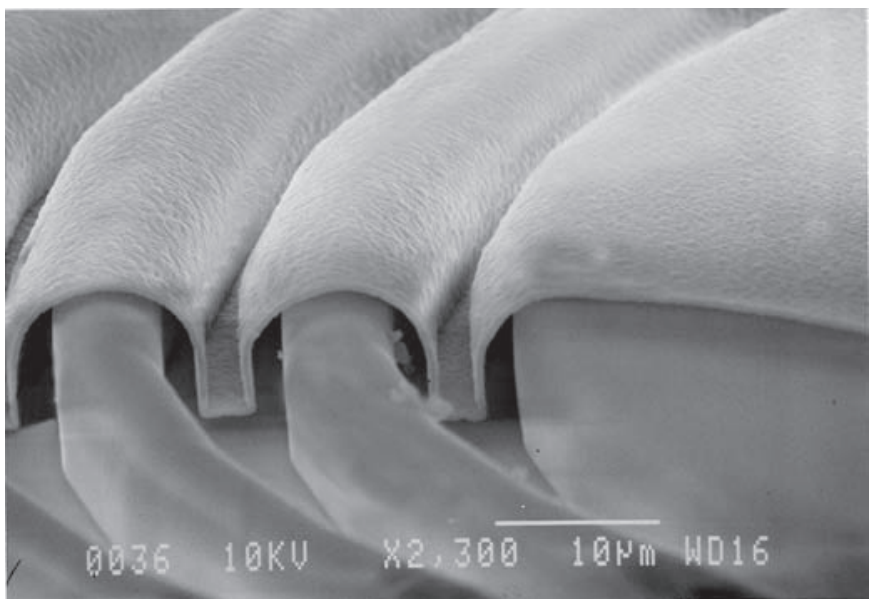

Figure 6. A corrugated diaphragm after the second polysilicon sacrificial layer is removed.

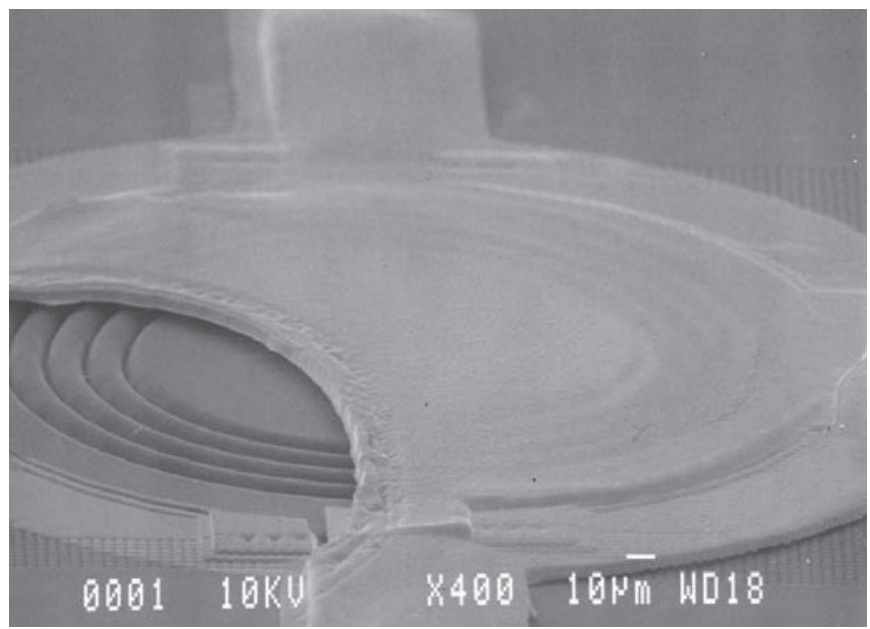

Figure 7. A pneumatically-driven microvalve with corrugated diaphragm after release in EDP.

polysilicon layer is now deposited to form the flow path through the valve and is beveled along $20 \mu \mathrm{m}$ of its outer edge to improve the ability of the diaphragm to seal to the valve cap. The second etch access holes are patterned to allow removal of this second sacrificial polysilicon layer (Figure 6). After the second sacrificial layer is etched by a 4 hour TMAH, a $7 \mu \mathrm{m}$-thick stress-balanced silicon dioxide/ silicon nitride/ silicon dioxide stack is now deposited and patterned to form the cap. (Figure 7) The thick cap is to maximize the deflection of diaphragm.

\section{RESULTS}

To confirm that the fabricated microvalve is suitable for a chronic drug-delivery device, it is necessary to measure the flow hydraulic resistance across system and the leak rate at certain pressure range. To measure the hydraulic flow resistance and leak rate across the drug-delivery system, the flow testing tools were set up as shown in Figure 8. The flow is driven using a volume flow controlled syringe pump (WPI UltraMicroPump) and a micro syringe (Hamilton $0.5 \mu \mathrm{L}$ ). Pressure is measured with a differential pressure transducer (Omega P26). The fluid is filtered through a $0.2 \mu \mathrm{m}$ in-line filter (Corning, Inc.) to remove trace particulates. Complete saturation of the flow system is ensured by using the procedure [3]: the testing device (Figure 9) is first back-filled with fluid using a vacuum pump system; then a flexible polyimide tube
Pressure Transducer (P1)

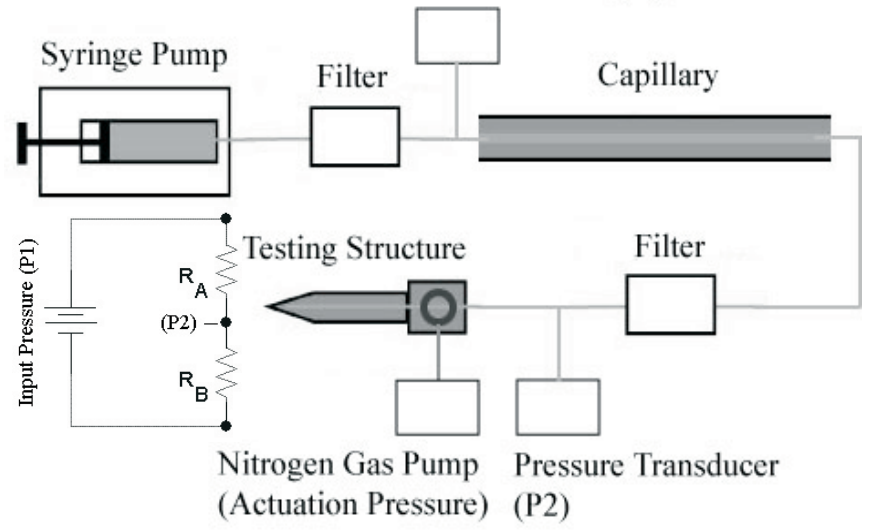

Figure 8. Schematic diagram of the flow testing tools illustrating pneumatic microvalve characterization. A small diagram shows a pressure-equivalent circuit. $R_{A}$ is a hydraulic flow resistance of a capillary and $R_{B}$ is a hydraulic flow resistance of a drugdelivery probe.

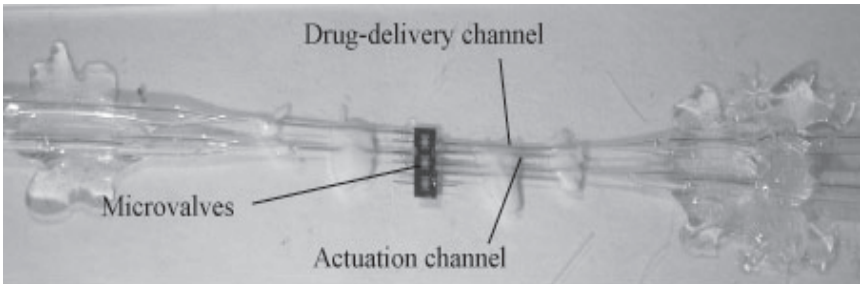

Figure 9. A picture of testing device. Each device has three pneumatic microvalves. Each microvalve has two actuation channels and one drug-delivery channel.

(WPI MicroFil) is inserted into the glass capillary; and finally a syringe assembly provides the required flow through the device. The seal between the syringe and the glass capillary of the device assembly is maintained with biocompatible epoxy.

\section{PRESSURE DROP MEASUREMENTS}

The pressure difference across the microvalve and its series microchannel has been analyzed to understand the drug delivery rate as a function of drive pressure. A pneumatic microvalve is composed of two channels. One is for drug-delivery and the other is for actuation (Figure 9). A first experiment was performed to measure the pressure variation (P2) across the system for water for different input pressures (P1) as shown in Figure 8. No pressure is applied to the actuation channel to make the valve open. A $30 \mu \mathrm{m}-$ ID, $10 \mathrm{~cm}$-long capillary (Polymicro Inc.) with a hydraulic resistance of $5 \times 10^{15} \mathrm{~Pa} \bullet \mathrm{s}^{\bullet} \mathrm{m}^{-3}$ and a diaphragm radius of $200 \mu \mathrm{m}$ was used. As shown in Figure 10 and 11, the total hydraulic resistance of the entire testing system was around $19.5 \times 10^{15}$ $\mathrm{Pa} \cdot \mathrm{s}^{\bullet} \mathrm{m}^{-3}$ at an input pressure of $10 \mathrm{kPa}$, which shows that the hydraulic resistance of the open-microvalve is $14.5 \times 10^{15} \mathrm{~Pa} \bullet \mathrm{s}^{\bullet} \mathrm{m}^{-3}$. At a flow rate of $513 \mathrm{pL} / \mathrm{sec}$ (Figure 11), the pressure drop across the system is $7438.5 \mathrm{~Pa}$, which is slightly lower than the simulated result of $8410 \mathrm{~Pa}$ using FLUENT. The difference results from the fact that the size of a fabricated microvalve is larger than that of the simulated one. As the input pressure (P1) increases, the crosssectional area of liquid-path in microvalve increases due to the liquid pressure to a flexible diaphragm for a microvalve and consequently the hydraulic flow resistance decreases. It results in 


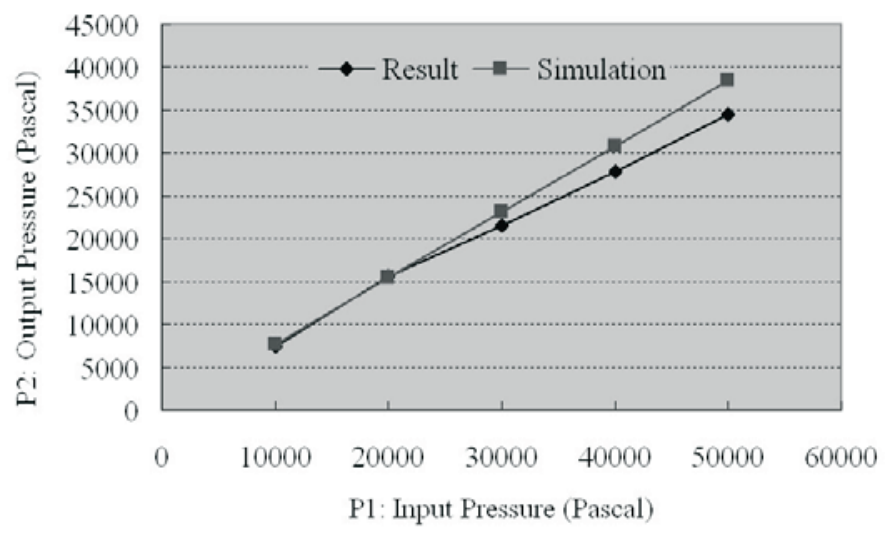

Figure 10. A pressure variation across the testing device as a function of input pressure (P1)

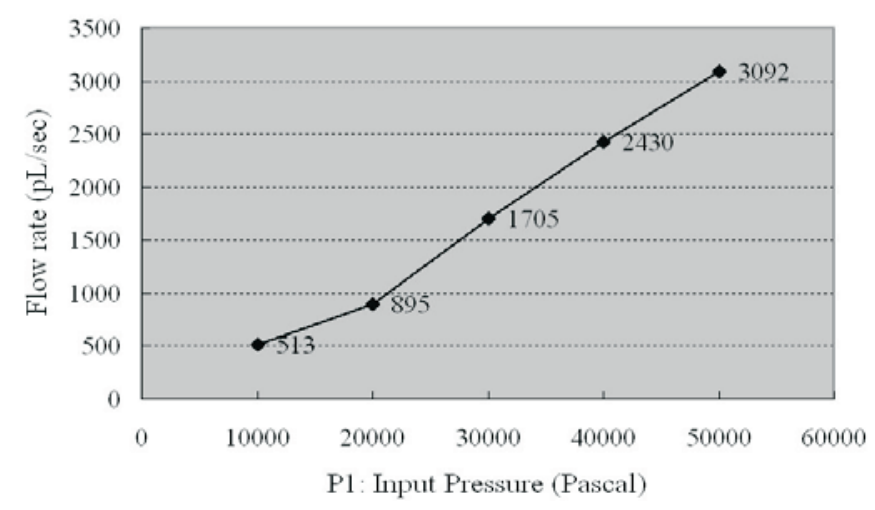

Figure 11. An open-flow rate variation as a function of input pressure (P1)

the nonlinearity of the flow rate (Figure 11) as the input pressure (P1) increases.

\section{LEAK RATE MEASUREMENT}

The pressure difference across the microvalve has been measured (Figure 12) to understand the leak rate (Figure 13) as a function of drive actuation pressure at the fixed input pressure of $10 \mathrm{kPa}$. A $10 \mathrm{~cm}$-long capillary with an inner diameter of $15 \mu \mathrm{m}$ (Polymicro Inc.) and a hydraulic resistance of $80 \times 10^{15} \mathrm{~Pa} \cdot \mathrm{s}^{\bullet} \mathrm{m}^{-3}$ was used with diaphragm radii of 180,200 , and $220 \mu \mathrm{m}$. The corresponding measured leak rates are 32,21 , and $15 \mathrm{pL} / \mathrm{sec}$, respectively, at an actuation pressure of $35 \mathrm{kPa}$ (Figure 13). These experiments show that the closed leak rate for a diaphragm radius of $200 \mu \mathrm{m}$ at $10 \mathrm{kPa}$ input pressure $(\mathrm{P} 1)$ is $21 \mathrm{pL} / \mathrm{Sec}$ and the open flow rate is $513 \mathrm{pL} / \mathrm{Sec}$ at the same pressure.

\section{CONCLUSIONS}

The pneumatically-actuated on-chip microvalve is completely compatible with the existing process for recording and stimulating probes and with the use of on-chip circuitry. It requires only two masks in addition to those for the standard probe process. As discussed earlier, the minimum effective flow rate of injected chemical is estimated at $500 \mathrm{pL} / \mathrm{Sec}$ and the amount of injected chemical that can be considered negligible can be taken at about $0.5 \%$ of a $100 \mu \mathrm{m}$ - diameter sphere, corresponding to $25 \mathrm{pL} / \mathrm{Sec}$ for a $100 \mathrm{mSec}$ pulse-duration. Therefore, this valve structure fulfills

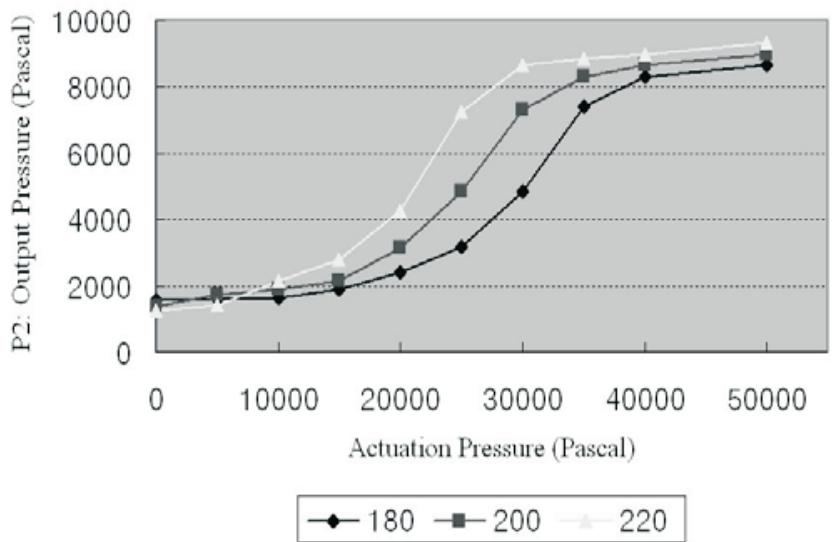

Figure 12. The pressure (P2) variation across the testing device as a function of actuation pressure at an input pressure (P1) of $10 \mathrm{kPa}$.

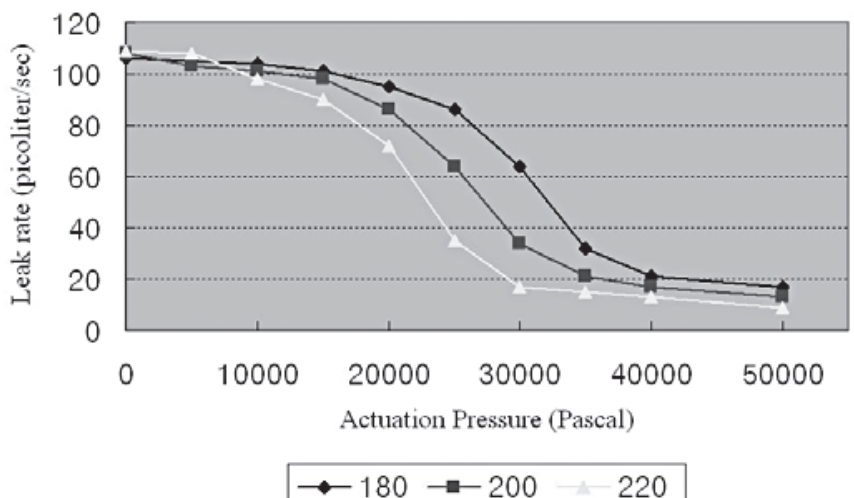

Figure 13. The leak rate measured as a function of actuation pressure at an input pressure (P1) of $10 \mathrm{kPa}$.

the requirements of leak rate $(<25 \mathrm{pL} / \mathrm{Sec})$ and minimum open flow rate $(>500 \mathrm{pL} / \mathrm{Sec})$ at $10 \mathrm{kPa}$ input pressure $(\mathrm{P} 1)$.

\section{REFERENCES}

[1] K. D. Wise, D. J. Anderson, J. F. Hetke, D. R. Kipke, and K. Najafi, "Wireless Implantable Microsystems: Electronic Interfaces to the Nervous System," (Invited), Proc. IEEE, pp. 76-97, January 2003.

[2] J. Chen, K. D. Wise, J. F. Hetke, and S. C. Bledsoe, Jr.," A Multichannel Neural Probe for Selective Chemical Delivery at the Cellular Level," IEEE Trans. Biomed. Engr., 44, pp. 760-769, August 1997.

[3] R. Rathanasingham, D. R. Kipke, S. C. Bledsoe, and J. D. McLaren, "Characterization of Implantable Microfabricated Fluid Delivery Devices," IEEE Trans. Biomed. Engr., v 51, n 1, pp.138145, January 2004.

[4] Y. Li, K. Baek, M. Gulari, K. D. Wise, "An In-Line Thermal Flowmeter with Vacuum-Based Thermal Isolation Chamber for InVivo Drug Delivery", IEEE Sensors 05, Los Angeles, November 2005.

[5] K. Baek, Y. Li, M. N. Gulari and K. D. Wise, "A Chronic Drug-Delivery Probe With Integrated Pneumatic Microvalves", 7th Int. Conf. on Miniaturized Chemical and BioChemical Analysis Systems ( $\mu T A S^{\prime}$ '05), Boston, October 2005. 